\title{
THE TREATMENT OF CARDIAC EMERGENCIES IN INFANCY
}

\author{
ELTON GOLDBLATT, B.Ss., M.R.C.P.(Ed.), D.C.H. \\ Consultant Padiatrician, Cardiac Clinic, Royal Liverpool Children's Hospital, Liverpool \\ Part-time lecturer, Department of Child Health, University of Liverpool.
}

THE treatment of cardiac emergencies in infancy is concerned mainly with the treatment of cardiac failure, cyanotic attacks. arrhythmias and cardiac arrest. The vast majority of infants requiring such treatment have some underlying congenital cardiac abnormality. Cardiac failure, if not associated with a congenital heart lesion, may be due to infections acquired in the perinatal period, such as viral myocarditis, toxic myocarditis in an overwhelming bacterial infection, to paroxysmal tachycardia, metabolic disorders such as glycogen storage disease, or may occur in the respiratory distress syndrome of the new born.

All congenital cardiac abnormalities may cause cardiac failure, the treatment of which should be thorough and intensive to enable further diagnostic investigations to be carried out, if indicated, with a view to curative or palliative surgery. In the infective and metabolic lesions there is no place for surgery and supportive medical treatment offers the only hope for the infant. Accurate diagnosis, however, is essential as unwarranted surgical interference in some cases may lead to untimely and avoidable death.

\section{Cardiac Failure in Infancy}

Most cases of cardiac failure are associated with some congenital cardiac abnormality, but, as mentioned, may be due to factors other than an anatomical abnormality.

\section{Physical Signs and Symptoms}

Where a congenital lesion is present there are usually the physical signs of the lesion, whereas in infective conditions or metabolic disorders there are often no specific diagnostic signs. A discussion on the treatment of congestive cardiac failure in infancy is incomplete without briefly reviewing the signs and symptoms.

In comparing the signs of cardiac failure with the familiar pattern seen in older children and adult patients, certain differences are apparent and stress should be laid on the following:-

(i) Hepatic enlargement:

This is the most important sign of cardia failure in infancy. It is easily and accuratel. elicited and changes in size are a good indicas tion of response to therapy.

(ii) Oedema and excessive weight gain:

Infants in cardiac failure may gain excessive weight although their food intake may be below average. This is due to fluid retention though oedema is not unusually apparent until the cardiac failure is severe. Again, by accurate daily weight records the infant's responseo treatment may be assessed. Unless excessive weight gain is checked by treatment oed will become manifest. This is usually most apparent on the dorsum of the feet, and periorbital oedema.

(iii) Dyspncea and tachypnoea:

This occurs in most infants in cardiac failure and may be associated with indrawing of the lower intercostal spaces and movement of the alæ nasi. It is often one of the earliest signs of decompensation. Dyspnoea is a frequent: symptom. Mothers may volunteer the in formation that the infant is breathless when feeding or even at rest. This is sometimes not noticed but there is a history of poor and difficult feeding, probably due to shortness of breath.

\section{(iv) Tachycardia:}

Usually there is a heart rate of $140-180$ pets minute, but occasionally decompensated infant may present with a bradycardia due, in somes to congenital atrioventricular block. The head rate may also be used as a guide to responseg of the infant to therapy.

(v) Cyanosis:

Peripheral cyanosis may be caused by cardia@ failure. Central cyanosis may be due to a\& 
intracardiac right to left shunt resulting from a congenital malformation. Cyanosis is therefore not necessarily a sign of cardiac failure. The degree of cyanosis is not a good indication of the severity of the cardiac failure, but may be helpful in the differential diagnosis of the underlying cardiac lesion.

\section{(vi) Signs in the lungs:}

In many cases the lungs may be clear clinically, and crepitations so frequently heard in the adult in cardiac failure are absent in the infant. If present, it may be impossible to differentiate between those sounds which are due solely to cardiac failure and those due to pulmonary infection, which may have precipitated the cardiac failure. Similarly, where inspiratory and expiratory rhonchi are present, they may be due to pulmonary oedema, bronchial infection, or both.

(vii) Raised jugular venous pressure:

This is not an easily elicited sign in infants due to their short, and often fat, necks. It is also difficult to elicit in the crying and struggling infant. Because of these factors, it should not be regarded as an essential for the diagnosis to be made. If, however, an elevated jugular venous pressure is noted, this is additional evidence of cardiac failure.

(viii) Signs of the cardiac abnormality:

If the underlying cause of cardiac failure is a congenital anatomical abnormality, the signs of this lesion may be apparent.

\section{(ix) Heart size:}

Accurate clinical evaluation of heart size is difficult unless there is marked cardiac enlargement. Cardiac enlargement alone is not evidence of cardiac failure.

\section{(x) Failure to thrive:}

This is a frequent symptom. Infants with congenital heart disease, although not in cardiac failure, may not thrive even if their intake is apparently adequate. On the other hand, the dyspnoeic infant cannot take normal requirements because of the effort needed to feed properly and fails to thrive because of inadequate intake. There is a history of normal feeding in only a small proportion of cases. (Goldblatt, 1962).

\section{Medical Management}

In discussing the medical management certain general measures should be considered before detailing the drug therapy. Intensive therapy is essential to improve the infant's condition as rapidly as possible to enable further investigations to be carried out in suitable cases with a view to surgical treatment.

There have been many studies in which the medical management of cardiac failure in infancy has been outlined. Although minor differences are noticeable in these studies, the general principles are similar in all and these will now be reviewed. (Kreidberg, Harvey and Lopez, 1963; Goldblatt, 1962; McCue and Young, 1961; Nadas, Rudolph \& Reinhold, 1953; Gasul and Arcilla, 1960; Keith, Rowe and Vlad, 1958).

\section{A. General Measures}

(i) Oxygen therapy: Infants in acute cardiac failure should be nursed in an incubator or oxygen tent with an oxygen saturation of approximately $50 \%$, or higher if necessary.

A high humidity is desirable to prevent plugs of mucus causing airway obstruction. This is an essential precaution due to the drying effect of tachypnoea on respiratory secretions.

(ii) Posture: For maximum comfort and respiratory excursion, the infant should be nursed on a tilted board which is placed in the cot. Various methods have been used to maintain the infant in this position such as strapping applied to the infant's back or some form of harness. (Goldblatt, 1962). In this position venous return is reduced and ventilatory movements are assisted by allowing free descent of the diaphragm. Propping up with pillows does not allow this as the flexed thighs pressing against the abdomen may restrict diaphragmatic movement.

(iii) Feeding: To prevent overdistension of the stomach which may further embarrass respiration, frequent small feeds are preferable to the normal feeding regime. Feeding requires great effort by the infant, and this is avoided by using a nasogastric tube. (A useful tube is the Argyle Premature Infant Feeding Tube, size 5 Fr.*). It can be left in situ for many days without causing undue discomfort or nasal irritation and infection. Feeds can be given via this tube even when the infant is asleep. By using a 1-2 ml. syringe feeds cannot be given more rapidly than if taken orally by a normal infant, and this prevents sudden overdistension of the stomach which may embarrass respiration even further.

\footnotetext{
*Manufactured by Aloe, Division of Brunswick,
} St. Louis. 
Usual feeding formulae are recommended, but in the acutely ill infant it may be necessary to use a low-salt milk ('Edosol'). When this is used careful electrolyte control should be maintained. Fluid restriction is never necessary, and maintenance of adequate hydration is essential particularly in cyanotic types of heart disease.

(iv) Travelling: When infants in cardiac failure have to be moved to centres for specialised treatment, it is essential to keep them cool by light clothing and few blankets. If necessary they should be sedated prior to transfer. Before departure the infant should be fed and, in the cases of long journeys, fed on the way. Arriving in an overheated, hungry state may aggravate the clinical condition because of the increased metabolic demands created by a crying, hungry, pyrexial infant. The failing heart may not be able to cope with the extra demands created by this state. When the above simple rules are observed these infants travel remarkably well.

\section{B. Drug Therapy}

(i) Digoxin ('Lanoxin') is the drug of choice as it is uniformly effective, easily administered, and serious toxic effects are rarely seen. Many doctors do not give large enough doses, and this leads to delay in adequate treatment and may complicate full digitalisation in a special centre. It is usually given orally, but may be given by the intramuscular or intravenous route when indicated.

Digitalising dose: $0.04-0.05 \mathrm{mg}$. per lb. body weight. (0.08-0.1 mg. per $\mathrm{kg}$.). This is given in the first twenty-four hours in four equal divided doses. If given parenterally, a quarter or half the calculated digitalising dose is given initially, and the remainder in three equal doses at six-hourly intervals.

Maintenance dose: Various authors recommend a sixth or more often a quarter of the digitalising dose as maintenance. No single dose, however, should be less than $0.0625 \mathrm{mg}$., except in premature infants or neonates, when the dose should be calculated according to weight. Tablets containing digoxin $0.0625 \mathrm{mg}$. are available. To avoid errors in dispensing these tablets are coloured blue.

The heart rate is a good rough guide to dosage, and treatment should be discontinued for 12-48 hours if the rate falls below 100 per min. in the infant under three months, and 80-90 per min. in infants between three and twelve months of age.
Vomiting may indicate overdosage, but mæึ be due to gastric irritation due to cardiac failuse when the drug may have to be given parenterally. The general condition of the infant shoutd be assessed before discontinuing treatment. $\underset{\vec{S}}{\vec{S}}$

(ii) Sedation: To ensure that the ill infagt has as much rest as possible sedation is extremely important part of the treatment. the acutely ill infant morphine is the drug choice. The recommended initial dose $1 / 600$ gr. per lb. body weight $(0.1 \mathrm{mg}$ per $1 \mathrm{~b}$. or $0.2 \mathrm{mg}$. per $\mathrm{kg}$.). In the premature infant and neonate approximately two-thirds to thre quarters of this dose is used. Subsequent doses can be altered after assessing the response the initial dose and should be given every four to six hours as required.

After the acute stage, to maintain mild sedis tion phenobarbitone should be given every six to eight hours. The recommended dose is 1/8-1/6 (8-10 mg.) for infants up to six months and gr. $1 / 4(15 \mathrm{mg}$.) for older infants.

For sedation for purposes of physical examination, recording of electrocardiograms an phonocardiograms, and accurate blood prest sure measurement, chloral hydrate is a usef al drug. The dose used is gr. 1/6-1/8 perlb body weight (10-20 mg. per kg.).

Toilet procedures should be carried out injections given preferably during periods maximal sedation.

(iii) Diuretics: In cases of acute pulmonary oedema mercurial diuretics, such as mersaly, are the most efficient, and therefore the drug of choice. The recommended daily dose 0.2-0.5 ml. given intramuscularly.

In less severe cases, and for maintenanee therapy, chlorothiazide is given in a daily dose of $20 \mathrm{mg}$. per lb. body weight. This dose may be increased to $50 \mathrm{mg}$. per $\mathrm{lb}$. if necessar\$. When using diuretics careful watch should be kept on electrolyte levels as low as serum potas. sium predisposes the myocardium to digoxin intoxication. In practice, however, potassiu音 supplements are rarely necessary.

(iv) Aminophylline: Bronchodilators are in dicated in the presence of pulmonary oedenf with bronchospasm. Aminophylline supposis: tories in a dose of 12.5-50 mg., depending of the weight of the infant, every four to six hours are often effective. In addition, ephedrine hydrochloride may be useful in a dose of gr $1 / 8-1 / 4$ (8-15 mg.), depending on age, give six to eight hourly.

(v) Antibiotics: It is extremely difficult, 
not impossible, to determine whether pulmonary signs are due to cardiac failure, to infection, or both. (Simpson, 1958). Infection may have precipitated cardiac failure or complicated it. For this reason antibiotics, usually penicillin and streptomycin, should be used in the acute stage. It may be necessary to use other antibiotics where indicated by bacteriological studies. Long term maintenance antibiotics may be necessary when recurrent infections precipitate repeated episodes of cardiac failure.

(vi) Correction of anaemia: Anaemia may be a precipitating factor in cardiac failure and if present should be treated, preferably by oral iron therapy, but a slow transfusion of packed cells in the severely anaemic infant may be necessary. In the case of cyanotic lesions it should be remembered that the "normal" haemoglobin is high and relative anaemia should be corrected.

\section{Surgical Management}

Ideally every congenital malformation should be corrected completely, but in a large number of cases this is not possible. In some it may be practical later but the best that can be offered in infancy is palliative surgery which will tide the infant over the acute emergency until older, when definitive corrective surgery may be undertaken with a much lower operative risk.

A frequent difficulty is to decide the optimum time for operation. In every case intensive medical treatment should first be given in an attempt to get the infant into the best possible condition, but sometimes, when response is not satisfactory an emergency thoracotomy should be undertaken without further delay. Response to treatment is assessed by falling respiratory and pulse rates, diminishing size of the liver and normal weight gain.

A detailed diagnosis of the malformation is of course desirable before surgical treatment is undertaken, and this should be established by cardiac catheterisation and angiocardiography, if the infant's condition permits. In the ill infant, however, these procedures carry a definite mortality risk or may worsen the infant's general condition. In such cases it may be preferable to rely upon clinical diagnosis and to carry out an exploratory thoracotomy with a view to corrective or palliative surgery. Diagnostic pressures at the time of surgery may be of some help but the difficulties of making an accurate diagnosis at the time of operation should be borne in mind.

At present, the operations done in this clinic and in many other centres for the more common lesions are as follows: -

1. Patent ductus arteriosus-ligation, but occasionally it is necessary to divide the ductus.

2. Ventricular septal defect with pulmonary hypertension-banding of the pulmonary artery. By narrowing the pulmonary artery, the pressure distal to the constriction is reduced to approximately a half or a third of the proximal pressure. By this procedure left to right shunting is diminished. In some centres closure is attempted in the first instance.

3. Atrio-ventricular canal with pulmonary hypertension-banding, but the results are not as good or encouraging as in "uncomplicated" ventricular septal defects.

4. Fallot's tetralogy-one of several procedures may be carried out. These include Blalock-Taussig, or Potts anastomosis, infundibular dilatation and/or resection. The purpose of these procedures is to increase pulmonary blood flow which in turn increases coronary and systemic arterial oxygen saturation.

5. Tricuspid atresia-cavo-pulmonary anastomosis, Blalock-Taussig or Potts anastomosis.

6. Pulmonary atresia-cavo-pulmonary anastomosis, Blalock-Taussig or Potts anastomosis.

7. Coarctation-resection. This is usually possible in the juxta and post-ductal type of coarctation, but not in the long preductal type of coarctation. In any case where surgery is indicated the arch of the aorta should be explored. (Waldhausen, King, Nahrwold, Lurie \& Schumaker, 1964).

8. Transposition of the great vessels-creation of atrial septal defect-Blalock-Hanlon procedure.

9. Total anomalous pulmonary venous drainage - an anastomosis is made between the pulmonary venous trunk and the left atrium. In some centres the trunk is tied off and the atrial septal defect closed at a second operation. (Williams, Richardson and Campbell, 1964). 10. Severe pulmonary stenosis - pulmonary valvotomy.

11. Aortic stenosis-aortic valvotomy should be attempted, but the mortality may be high because there is often an extremely small valve ring associated with a small left ventricle and hypoplastic ascending aorta.

The overall mortality rate of infants with cardiac failure is approximately $50 \%$. (Goldblatt, 1962). With improving surgical and anaesthetic techniques this will be reduced but 
there will always be a relatively high mortality because of the number of complicated lesions causing cardiac failure which are not amenable to surgical correction.

\section{Cyanotic Attacks}

Many paediatricians interpret the term "cyanotic attack" as an episode in which an infant with a cyanotic cardiac lesion becomes increasingly cyanosed on crying, feeding or when cold. This is a common occurrence in these infants and it should be remembered that a change in colour alone is "physiological" and not necessarily serious.

True cyanotic attacks are spontaneous and apparently occur in infants with cyanotic cardiac lesions associated with pulmonary oligaemia such as Fallot's tetralogy, pulmonary and tricuspid atresia and transposition of the great vessels with pulmonary stenosis. They have been shown to be due to temporarily increased obstruction of the right ventricular outflow tract with an increased right to left shunt. During the attack, because of the diminished flow through the right ventricular outflow tract, the systolic murmur may become shorter, softer, or may entirely disappear. (Wood, 1958; Braudo and Zion, 1959 and 1960).

Clinically a cyanotic attack is usually characterised by a shrill cry or scream which is different to the normal cry of the infant. It is difficult to pacify the infant and he may continue crying until exhausted, when he falls into a heavy sleep. On waking he may be as well as prior to the attack.

Associated with the cry there is a change in colour, often to a deeper cyanosis or there may be a greyish blue colouration of the lips and face. In addition the infant may sweat excessively. The respiratory rate increases, the eyes may roll upwards and the infant may lose consciousness for a variable period. Sometimes, there is a twitching. Although recovery usually takes place, an occasional attack is fatal.

The treatment is urgent. In the first place morphia should be administered as rapidly as possible as this shortens the attack and enables the infant to rest. Oxygen should be administered to relieve the associated anoxia, although the attacks are not relieved by oxygen alone. Procaine hydrochloride given intravenously has an immediate but short lived effect. (Braudo and Zion, 1959). Cyclopropane anaesthesia has also been shown to be effective (Wood, 1958), but for obvious reasons is not a practicable method of treatment in the majority of cases.
Increasing frequency or severity of attackiss should be regarded as an indication for in mediate surgical treatment. As the attacks usually occur in infants with cyanotic heart lesions with pulmonary oligaemia, the surgic approach usually consists of an operation designed to increase pulmonary blood floy such as a systemic-pulmonary anastomosis, of infundibular dilatation or resection where pos sible. Cyanotic attacks should cease after $\frac{0}{9}$ sucessful operation. Even in the best hands however, results of anastomotic procedures i infants under the age of three months are uniformly bad.

\section{Arrhythmias}

All types of arrhythmia seen in adults and older children may occur in infancy, but are not common. For the purpose of this discus sion the most frequent arrhythmias encountere are paroxysmal tachycardia and complete heare block. The former is usually a supraventricu lar tachycardia. In fifty per cent of the series described by Nadas (1957) there was no obvious explanation for the tachycardia, whilst the res mainder were associated with some congenitats cardiac abnormality, the Wolff-Parkinson? White syndrome or other factors which nfarg have precipitated the arrhythmia.

A few of the infants were not ill, but th majority were extremely ill, the clinical picture resembling severe pneumonia or septicaemia Infants with paroxysmal tachycardia may be restless and irritable or present with feeding difficulty with associated vomiting. Others become dyspnoeic, pale and clammy.

The majority of cases present in the first few months of life. Of those without any known. predisposing factors, the majority are males.

The development of cardiac failure depends on the heart rate, the duration of the tachyo cardia and the age of the infant (the younger, the greater the risk of cardiac failure developing).

The treatment should begin with reflex vaga: stimulation such as carotid sinus or eyebalf pressure. If this is not successful, prostigmine may be tried but if there is evidence of cardiac failure the principles of treatment are similar to those already discussed. Maintenanco digoxin should be continued for at least đ? month, and longer if further attacks occur. In cases with the Wolff-Parkinson-White syn:drome, if the tachycardia does not respond to digoxin, quinidine may be the drug of choicen to control the tachycardia, and maintenance therapy may be necessary. The dose is $100-2000$ 
mg. every two hours for eight doses. The dose should be increased each day until the tachycardia is abolished or toxic effects are noted. Maintenance therapy given three or four times a day may have to be continued for some months.

Complete congenital heart block does not usually constitute a medical emergency as there may be no symptoms due to compensatory mechanisms of an otherwise normal heart. There may, however, be symptoms of an underlying cardiac malformation. Except for the occurrence of Stokes-Adams attacks, which are rare, there is no indication to attempt to increase the heart rate.

\section{Cardiac Arrest}

Cardiac arrest may be regarded as the most serious of all arrhythmias. It may occur in infants with cardiac lesions in heart failure, during investigation or surgery or with some intercurrent illness. It may also occur in infants with normal hearts who have severe infections, are dehydrated, have been accidentally poisoned or have inhaled vomit often related to feeding.

The management in all cases is similar and based on well established principles. These include:

(i) Maintenance of an adequate airway; when possible intubate the infant.

(ii) Maintenance of an adequate cardiac output by external massage is easy in an infant. At the same time, artificial respiration is carried out. This is essential until the infant has been intubated and is respired by intermittent positive pressure.

(iii) Correction of the metabolic acidosis, which occurs rapidly, by sodium bicarbonate (2.5\% solution) intravenously. The amount given should be calculated according to the base deficit, but as an emergency measure $10-20 \mathrm{ml}$. should be infused and repeated if necessary at 10-30 minute intervals until the deficit is corrected.

Intracardiac injections of adrenaline and calcium chloride may also be useful in reestablishing cardiac action.

Once cardiac action has returned it may be necessary to use a mechanical ventilator for a period.

\section{Discussion}

There have been several reviews of the incidence, signs, symptoms and treatment of cardiac failure in infancy. (Keith, 1956; Goldblatt, 1962; Kreidberg and others, 1963).

It is common experience that the mortality of both medical and surgical treatment of congenital heart lesions is extremely high in the first three months of life, and it is during this time that the largest percentage of infants with such malformations develop cardiac failure. (Goldblatt, 1962).

Among the most frequent lesions causing cardiac failure in infancy are transposition of the great vessels, coarctation of the aorta, aortic atresia, atrioventricularis communis, ventricular septal defect, patent ductus arteriosus, single ventricle, and other complicated cyanotic lesions. A high mortality is to be expected because of the complexity of some of the lesions which are not amenable to palliative or curative surgery. There is, however, a need for improved diagnostic and surgical techniques to reduce further this mortality.

Where facilities for investigation and treatment are not available, early transfer to a specialised paediatric cardiological unit is desirable in order to institute intensive therapy with minimal delay with a view to early diagnosis and operative treatment. This will help to reduce the high mortality.

With the recent development of relatively simple methods of determining $\mathrm{pH}, \mathrm{pCO}_{2}$ and standard bicarbonate levels, increasing attention is being paid to the correction of acid-base disturbance which sometimes occurs in infants with cardiac failure, and this may be an extremely important addition to the treatment outlined above (Jones, 1964).

\section{Summary}

The signs, symptoms and management of cardiac failure, cyanotic attacks and cardiac arrhythmias are discussed. General principles of surgical treatment are mentioned.

Standard diagnostic procedures have their limitations in these ill infants, and the mortality rate following surgery is still high, although it is falling with improved surgical and anaesthetic techniques. Considerable further improvement in both diagnostic and surgical methods is required if more of these infants are to survive. 


\section{REFERENCES}

Braudo, J. L., Zion, M. M. (1959): The cyanotic (syncopal) attack in Fallot's tetralogy. Brit. med. J. i, 132艿

BRAUDO, J. L., Zion, M. M. (1960): Cyanotic spells and loss of consciousness induced by cardiac cathetê isation in patients with Fallot's tetralogy. Amer. Heart J. 1, 10.

Gasul, B. M., ARcilla, R. A. (1960): Prophylaxis and treatment of cardiovascular emergencies in infarts and children. J. Amer. med. Ass. 44, 172.,

GoldblatT, E. (1962): The treatment of cardiac failure in infancy-Review of 350 cases. Lancet, ii, 2宇

JONES, R. S. (1964): Personal communication.

KeITH, J. D. (1956): Congestive Heart Failure, Pediatrics, 18, 491. Keith, J. D., Rowe, R. D., Vi.AD, P. (1958): Heart Disease in Infancy and Childhood. New York: Maao-
millan.

KREIDBerG, M. B., Harvey, L. C., Lopez, W. L. (1963): Treatment of cardiac failure in infancy ana childhood. New Engl. J. Med. 268, 23.

McCue, C., Young, R. B. (1961): Cardiac failure in infancy. J. Pediat. 58, 331.

NAdAS, A. S., RudolPh, A. M., Reinhold, J. D. L. (1953): Use of digitalis in infants and childre clinical study of patients in congestive heart failure. New Engl. J. Med. 248, 98.

Nadas, A. S. (1957): Pediatric Cardiology. Philadelphia: W. B. Saunders.

SiMPSON, K. (1958): Heart failure in infants. Proc. roy. Soc. Med. 51, 1022.

Waldhausen, J. A., King, H., Nahrwold, D. L., LuRIe, P. R., Schumaker, H. B. (1964): Manage ment of coarctation in infancy. J. Amer. med. Ass. 187, 270. Williams, G. R., RICHARDSON, W. R., CAMPBell, G. S. (1964): Repair of total anomalous pulmonafy
venous drainage in infancy. J. thorac. cardiovasc. Surg. 47, 199.

Wood, P. (1958): Symposium on congenital heart disease-attacks of deeper cyanosis and loss of con sciousness (syncope) in Fallot's tetralogy. Brit. Heart J. 20, 282. 